\title{
A apropriação/transformação do estado atual da prática e da formação em psicologia: contra a miséria da psicologia
}

\author{
Bader Burihan Sawaia* \\ Pontifícia Universidade Católica de São Paulo, Programa de Estudos Pós-Graduados em Psicologia Social. São Paulo, SP, Brasil
}

\begin{abstract}
Patto, M. H. S. (2012). Formação de psicólogos e relações de poder: sobre a miséria da psicologia. São Paulo, SP: Casa do Psicólogo.
\end{abstract}

Nos limites de uma resenha cabe, de início, apresentar os textos que compõem a coletânea Formação de psicólogos e relações de poder: sobre a miséria da psicologia, mas isso já está muito bem feito na apresentação de Maria Helena Patto, sua organizadora. Tampouco resumirei o seu conteúdo. Para que serve o resumo se o texto clama por ser lido?

Contentar-me-ei em refletir sobre o que, em minha opinião, constitui a grandeza do livro: transformar, a golpes analíticos, um drama humano em acontecimento. Explico: trata-se de um livro gestado no e pelo calor de um trágico fato ocorrido em 2008 - o assassinato de duas crianças pelo pai e pela madrasta, após serem devolvidos à família pelo Conselho Tutelar, ao qual haviam sido encaminhados por denúncia de maus tratos. Tal decisão foi baseada em pareceres de uma equipe de profissionais, entre eles um psicólogo, que apresentava os meninos como "pessoas que manipulam a realidade para conseguir vantagens" (p. 18).

Um "bando irascível"1 de intelectuais intransigentes em seus princípios, convocado por Maria Helena Patto, sai do conforto da crítica acadêmica para ajudá-la a se manifestar publicamente sobre os "males" da própria ciência, rompendo o corporativismo e a tolerância acadêmica. Dessa forma, transforma algo problemático - um crime em acontecimento/problematizante, com carga inovadora.

Acontecimento é o que força o pensar e altera formas de agir, oferecendo "a possibilidade do impossível", afirma Badiou (2010, p. 23), tendo a cautela de completar que o acontecimento abre possibilidades analíticas, mas não dá certeza acerca da possibilidade de sua realização.

É exatamente isso que o livro faz com um fato policial trágico e triste que poderia acabar no esquecimento: transforma-o em uma força para pensar "os males da psicologia e da formação do psicólogo" (p. 13). 1 Expressão usada por Edson Passetti em "Revirando a psicologia: um
decálogo político", na orelha do livro.

* Autor correspondente: badbusaw@pucsp.br
Estamos diante de um quadro gravíssimo e inaceitável, não só porque há psicólogos vitimando pessoas, mas também porque a credibilidade de uma ciência e profissão que conta com excelentes pesquisadores e profissionais capazes de contribuir para a construção da cidadania está ameaçada. (p. 20)

A crítica à psicologia como ciência da adaptação e da normatização não é novidade. Já foi feita indiretamente pelos mestres da suspeita: "Freud, Marx e Nietzsche" (p. 205). Nos anos 1970, essa crítica contra o engajamento ideológico das ciências sob o manto da neutralidade irrompe com muita força na psicologia, motivada em parte pelo movimento antimanicomial e pela antipsiquiatria, e na América Latina pelo apelo ao compromisso social da psicologia ante os regimes militares e a miséria da população, lançado especialmente por Lane (1984) e MartinBaró (1986).

Este livro segue essa tradição, atualizando política e academicamente tal crítica, mas vai além. Confronta-nos com um paradoxo epistemológico angustiante: aceitamos a critica à ideologização da ciência, à neutralidade do método científico, à lógica eugenista, higienista e adaptadora da psicologia, mas continuamos a reproduzir esses valores em nossa pesquisa e ação profissional. Fazemos isso de diferentes e sutis formas como, por exemplo, na formação do psicólogo, diminuindo espaço e tempo para a crítica e a reflexão em nome do ativismo, da preparação para o mercado de trabalho e da eficácia das ações segundo os parâmetros da manutenção da ordem social (p. 212).

A luta em que ele se engaja não é a de demonstrar a universalidade de uma teoria em relação a outra ou de promover combates entre teorias ditas "reacionárias e progressistas" (p. 133), mas de refletir o quanto nossa ação está restringida pelo mesmo raciocínio que sustenta pressupostos dogmáticos, "um fato nada raro em laudos psicológicos: a mera reprodução de preconceitos e a ratificação do que já estava decidido de antemão - mandar as crianças de 
volta para casa" (p. 18). É uma luta que escapa de qualquer forma de maniqueísmo e pensamento linear. Critica o racionalismo sem destruí-lo: "é preciso pois uma razão alargada que se compreenda na vida" (p. 211). Critica a prática psicológica, mas não anula a importância social da dimensão subjetiva e não trata o psicólogo como uma categoria homogênea, tanto que dialoga com dois públicos, os que "precisam ser despertados" e os que já estão em vigília e até insones pela angústia das impossibilidades, instigando todos a se defrontarem com seus próprios dilemas. Ao mesmo tempo, lembra com propriedade que não se pode cair na culpabilização individual: "embora responsável pelo parecer que redigiu - e por isso deveria ser interpelado pelos órgãos oficiais que cuidam do exercício da profissão, não se pode simplesmente imputar ao profissional a barbárie que ajudou a perpetrar" (p. 144), o que não significa a permissão para que ele continue a alimentá-la.

O texto está organizado para ir gradualmente ampliando nossa visão crítica. Cada leitura traz novas reflexões e informações sobre as barbáries que a ação profissional do psicólogo está ajudando a manter, com foco nas atividades de avaliação psicológica e de formação do psicólogo.

Já no primeiro texto, Patto e Leser deixam claro o que pretendem combater: a pratica psicológica indiferente e fria sustentada pela "crença de que as ciências humanas produzem conhecimentos acima de qualquer suspeita, garantidos por métodos de pesquisa que se dizem objetivos e neutros" (p. 19). Uma crença que sustenta a ideia de discurso psicológico competente e de poder inquestionável que autoriza o profissional a dizer sobre o íntimo das pessoas, sem entender a complexidade, a gravidade e os perigos de trabalhar com a dimensão subjetiva.

O texto seguinte, de Shine, coloca o leitor dentro da função de psicólogo/avaliador/perito para refletir sobre os risco institucionais

da avaliação e dos laudos chegarem a conclusões sobre bases inadequadas, especialmente, na definição do que é o melhor interesse da criança, pelo fato dela ser sempre feita sob demanda do outro. . . na relação triangular entre o operador do direito, que é o demandante do laudo, e a família, como sujeito/ objeto da ação investigativa. (p. 51)

A seguir vêm os textos que explicam, a partir da análise da história das ideias psicológicas, a permanência no campo científico do biologicismo e do seu correspondente "viés preconceituoso a respeito da criança" e " $d a$ família", tese demonstrada por meio de informações ricas e análise perspicaz por Gomes Lima e Mandelbaum, respectivamente.

Gomes Lima analisa os escritos de um dos pioneiros da psicanálise no Brasil (Durval Marcondes), apontando que os pressupostos enfatizados por ele estão, até hoje, presentes em nossa ação, especialmente a ideia de "que a família pobre é desestruturada e negligente e a infância é, em essência, patológica; se deixada livre, ira realizar seus desígnios doentios e se terá a desordem" (p. 90). Dai a sua proposta de instalar a "higiene mental escolar como o lugar legítimo para a prescrição das influências modeladoras corretas" (p. 91). Com base nesta análise, o autor conclui que: "a psicologia exerce uma ação crucial no governo das subjetividades" (p. 104).

Na mesma direção, Mena apresenta uma hipótese original e instigante, que talvez não tenha sido seu propósito. Por meio da obra de um jurista brasileiro do inicio do sec. XX, Evaristo de Moraes, um dos pioneiros da incorporação das desigualdades socioeconômicas como possíveis causas da criminalidade, que esta inclusão não foi e não é suficiente para superar o biologicismo dominante nas avaliações judiciais. Ao contrário, ao relacionar pobreza com "degeneração orgânica e esta com a criminalidade, o autor endossa sutilmente as teses da Eugenia, reforçando epistemologicamente a naturalização da desigualdade. Ele não só realiza uma mudança de perspectiva na análise da determinação criminalidade, como "aponta também uma mudança na forma de tratá-lo, defendendo uma educação preventiva e medidas socioeducativas curativas dos determinismos. Assim a tese de que 'a criminalidade é uma doença se metamorfoseia em' a pobreza é uma doença" (pp. 78-79).

No decorrer dessas leituras, uma pergunta começa a nos fustigar:

Por que ainda permanecem os pressupostos que já foram enfaticamente criticados pelos riscos que ofereciam de operar uma redução ideológica biologizante, benéfica a manutenção do que ai está, e que mantém a psicologia como ciência da normatização? E mais, uma permanência que se faz com ares de inovação na forma de apresentar-se,-mas com o mesmo efeito danoso à vida. Marx (1852/2000) já nos alertou para este processo histórico: "A história se repete, a primeira vez como farsa, a segunda como tragédia".(falta aspas) Continuando a leitura encontramos mais reflexões teóricas que indicam pistas para a busca de respostas à indagação acima nos textos de Rodrigues, Ramos, Sass, Crochík e Patto. Reflexões ricas baseadas em um leque multivariado e complexo de ideias (Lacan, Zizek, Adorno,Horkheimer, Marx, Foucault, Deleuze, MerleauPonty) mas que partilham do mesmo pressuposto, de que o saber psicológico é gestado e só pode ser compreendido na sua inserção sócio-histórica como afirma Rodrigues: "podemos perceber que um psicologia que se proponha a compreender a subjetividade ... deve, antes de mais nada, poder pensar seu objeto historicamente, o que significa pensar a si própria criticamente" (p. 164).

As pistas para orientar a análise dessa relação entre sociedade e subjetividade são diversas, mas dentre a variedade apresentada duas se destacam: uma foulcaultiana e outra frankfurtiana, que ouso sintetizar, mesmo correndo o risco da simplificação, mas com a certeza de que o leitor pode encontrar a complexidade na leitura dos textos. São elas, respectivamente, a relação direta e indireta entre política e discurso científico e o processo de tecnicização progressiva do saber, pela racionalidade tecnológica 
dominante no mundo administrado. A pista iluminada por Foucault nos orienta a buscar explicação na maneira como o "discurso cientifico psicológico se encontra colocado num sistema de correlações com outras práticas, num jogo de poder-saber", que, segundo Rodrigues, "na situação em apreço, são as de culpabilização, de identificação de inimigos internos e/ou perigos biológico, cisão moral entre bons cidadãos e rebotalho social" (p. 133). De outro, a pista aberta pelo pressuposto adorniano que nos defronta com a força do tecnicismo, subproduto da sociedade administrada, na forma de indiferença, de comodismo, de corporativismo, do interesse exclusivo por si e de seu correlato a dificuldade de sensibilizar-se com o sofrimento dos outros (p. 138). ${ }^{2}$

Em meio a todos os tormentos que essas ricas reflexões comportam, outra pergunta se impõe: quais as perspectivas de superação? Elas não se mostram muito problemáticas nessas duas proposições?

Problemáticas, sim, mas não impossibilitadas, o livro nos responde. A crítica não esgota todas as forças de nossos espíritos e corpos, ao contrario, quando sólida e competente alimenta a transformação. Torna-se práxis.

A decisão de deixar para o final do livro o texto de Furlan sobre filosofia explicita o alvo da ação transformadora priorizado por sua organizadora: a formação reflexivo-critica do psicólogo, filosoficamente fundamentada, para nos ajudar a reconhecer que "nossa ciência tem índole mutável, podendo ser arrebatada e corrompida pelas determinações sócio-históricas" (p. 143).

É preciso urgente escapar da lógica que preside os cursos de formação do psicólogo, dominado pelo tecnicismos e pelo ensino antipensamento e antirreflexão, sobre teorias e conceitos normatizantes que patologiza e criminaliza os que já sofrem a perversidade da desigualdade socioeconômica. Para tanto propõe que os cursos devam considerar a filosofia. (p. 143)

"É preciso que o psicólogo tenha uma formação sociológica que lhe permita perceber que a dor de seu cliente é real, pois é socialmente produzida", reforçam Crochík e Patto (p. 143).

A filosofia, não para aprisionar o psicólogo a ideias abstratas e racionais, mas para definir um necessário campo de batalha : o epistemológico e teórico, bem como a sua arma mais importantes: a reflexão critica contra as astúcias do processo de fossilização do pensamento conservador e adaptador em conceitos aparentemente inovadores. Portanto, uma filosofia que é ao mesmo tempo uma teoria social capaz de reforçar as pistas foucaultiana

2 O livro nos afeta de modo a nos motivar a complementá-lo com as ideias que ele nos suscita. Eu completaria essas pistas destacando a exploração econômica, a ideologia,e a mercantilização dos homens e o consumismo. e frankurtiana de reflexão/ação psicológica revolucionária.

Vejamos algumas possíveis reflexões nesta direção: Não seria revolucionário refletir, à semelhança de Foulcault (2004), sobre o por quê cada escola da psicologia define uma dimensão exclusiva do homem, sexualidade, linguagem, consciência, cognição, comportamento, como o único sismógrafo da subjetividade? (p. 218).

O mesmo não poderia ser dito em relação à reflexão sobre os motivos pelos quais a emoção perdeu a luta contra a razão e aparece na historia das ideias como "perturbatio animi" (Rouanet, 1985), um variável do psiquismo que deve ser eliminada, para dar lugar a verdade e à civilidade? Porque esta ideia permanece a despeito de vários pensadores terem demonstrado o contrário, como indica a citação feita por Rodrigues (por indicação de Patto) "Aqui cabe marcarmos o valor revolucionário atribuído por Marx à vergonha" (p. 162).

Ou ainda refletir se o antigo hábito de explicar a desigualdade por uma inferioridade inata de certas raças não foi substituído pela representação do direito inalienável de toda comunidade a sua forma tradicional de viver. Não seria essa uma forma do Estado produzir a reconciliação com a desigualdade pelo respeito aos valores culturais e pela liberdade de escolha.

Também não seria desestabilizador perguntar se as ações dos psicólogos não estão atravessadas pela desigualdade social, bem como alguns de seus conceitos consensuais como o de família desestruturada, menor, esforço pessoal, autoestima, criança incapaz de conhecer suas necessidades. "Informada, ao mesmo tempo, por estereótipos e preconceitos a respeito da infância e da infância nas classes subalternas, o olhar da psicóloga capturou os dois meninos como delinquentes reais ou potenciais" (p. 142).

Ousando ainda mais, que tal perguntar se a ideia de que é a pessoa quem decide sobre sua vida e felicidade não revelaria a indiferença transvestida de neutralidade e poderia ajudar á promover a subjugação das minorias por escolha delas mesmas.

Estas reflexões se tornam mais necessárias quando se constata o aumento de cargos oferecidos aos psicólogos pelo Estado, o que já vinha ocorrendo nas empresas. A psicologia está sendo chamada a ocupar cada vez mais funções nas políticas publicas de saúde, de assistência e nas ligadas ao sistema judiciário, para trabalhar a dimensão subjetiva das questões sociais. Assim, ela se defronta com a pobreza, com a desigualdade e com as relações de poder. A literatura já vem apontando os riscos dessas novas posições reforçarem o papel da psicologia de vigilância, normatização e de mediação da judicialização da vida dos que estão incluídos perversamente pela pobreza e pela exploração.

Será que a valorização da subjetividade e dos seus respectivos especialistas no trato com a desigualdade, não revelaria a concepção de que a subjetividade é dimensão fundamental na manutenção de uma ordem social excludente. (seria uma interrogação?) 
Aproveito aqui para apontar que a desigualdade social e a pobreza atravessam os textos desta coletânea, embora não estejam explicitamente salientados como o tecnicismo e a verdade científica como dispositivos disciplinares. Elas aparecem na critica ao higienismo e ao discurso eugênico: "ideias que patologizaram a infância "sobretudo quando se tratava de crianças de classe populares, supostamente povoadas de pais portadores de patologias mentais e de toda sorte de moralidade que os tornam negligentes" (p. 12). Também elas estão na base do problema desencadeador do presente livro como escreve Patto: "viés preconceituoso a respeito do comportamento de duas crianças pertencentes a um segmento de classe que desde os primórdios das ciências humanas é visto de forma negativa : primitivos, portadores de taras, indolentes, imorais, perigosos- preconceito cientifico" (p. 11). ${ }^{3}$

Antes de finalizar é preciso ressaltar que não se pode desconhecer as forças de resistência a esse processo de reposição do mesmo e de (des)sensibilização do psicólogo, e é preciso saudar os competentes esforços de excelentes pesquisadores e profissionais (ações merecedoras também de publicização e análise) que estão angustiados frente aos bloqueios de suas ações e pedem socorro.

$O$ presente livro é um esforço para que este não seja "um pedido de socorro á parede" (p. 137). De um fato que

3 Para completar ler Patto (1997). ficaria esquecido nas páginas policiais, reforçado por nossa insensibilidade e indiferença, ele cria um "acontecimento" que nos angustia pela demonstração, que por traz das aparentes transformações do pensamento psicológico subjaz as forças conservadoras e ideológicas da sociedade de classes, mas também nos potencializa ao apontar a filosofia e a formação como espaços de superação. $\mathrm{O}$ que não significa considerar que a formação e a reflexão são suficientes para evitar a barbárie da qual ela é produto, mesmo porque é uma concepção negadora dos pressupostos sustentadores de todos os textos aqui apresentados.

O que desde o inicio venho apontando como o grande mérito da coletânea organizada por Maria Helena Patto é o seu senso de apropriação-transformação que tira a psicologia do marco técnico/instrumental e despolitizado e a restabelece como campo de ação e reflexão. Uma práxis capaz de orientar rupturas nas ideias e ações referentes às questões humanas e de "criar uma zona comum de troca de conhecimentos empenhados em projetos de libertação" (Hardt, 2010, p. 143) como o de impedir que a "miséria da psicologia" não se alastre junto com a miséria da sociedade e que o bloqueio da primeira seja uma força de resistência à última.

Afinal, ela é responsável por duas formas de saberes: "quer extraindo saber dos indivíduos, quer elaborando saber sobre os indivíduos" (Muchail, 2004, p. 69).

\section{Referências}

Badiou, A. (2010). La idea del comunismo. In A. Hounie (Comp.), Sobre la idea del comunismo (pp. 155-166). Barcelona: Paidós.

Foulcault, M. (2004). Sexualidade e solidão. In M. B. Motta (Org.), Ditos e escritos (Vol. 5). Rio de Janeiro, RJ: Forense Universitária.

Hardt, M. (2010). Lo común en el comunismo. In A. Hounie (Comp.) Sobre la idea del comunismo (pp. 129-144). Barcelona: Paidós.

Lane,S. T. M. (1984). A psicologia social e uma nova concepção do homem a psicologia. In S. T. M. Lane \& W. Codo, Psicologia social: o homem em movimento. São Paulo, SP: Brasiliense.
Martin-Baró, I. (1986). Hacia una psicología de la libertación. Boletín de Psicología, (22), 219-231.

Marx, K. (2000). Dieciocho de Brumario de Luis Bonaparte. Recuperado de http://www.marxists.org. (Trabalho original publicado em 1852)

Muchail, S. T. (2004). Foucault simplesmente. São Paulo, SP: Loyola 69.

Patto, M. H. S. (1997). Para uma crítica da razão psicométrica. Psicologia USP, 8(1), 47-62.

Rouanet, S. P. (1985). A razão cativa: as ilusões da consciência: de Platão a Freud. São Paulo, SP: Brasiliense. 